\title{
Home-based Art Therapy in Hong Kong
}

\author{
香港在家藝術治療發展 \\ Ling Cheun Bianca Lee \\ Hong Kong Association of Art Therapists, Hong Kong, China
}

\begin{abstract}
This article investigates the validity and impact of home-based art therapy practices in Hong Kong by highlighting the needs of the home environment, the unique structure of the therapeutic relationship, and the appropriate treatment planning. Additionally, general and culturally specific ethical concerns are examined within the context of home-based mental health care. A homebased art therapy case study is presented to illustrate the benefits and complexities of such a modality. The possibilities of further development in home-based art therapy in Hong Kong are examined.
\end{abstract}

Keywords: Hong Kong, home-based art therapy, mobile art therapy

\section{摘要}

本文透過審視家庭環境的需求、治療關係的獨特結構以及適當的治療計劃，對香港居家 藝術治療工作的認受性及效力進行探討。此外，在以移动心理治療為基礎的前提下，對 一般及特定文化的道德考慮納入分析。運用居家為基礎的藝術治療案例，展示說明其好 處及這形式包含的複雜度。對香港居家藝術治療進一步發展的可能性進行探討。

關鍵字 : 香港，居家藝術治療，移动藝術治療

\section{Introduction}

The formal establishment of an art therapy field in Hong Kong is a recent development. The art therapy field was formalized when the Hong Kong Association of Art Therapists (HKAAT) was established 16 years ago (HKAAT, 2019). The number of foreign-educated and registered art therapists has grown in Hong Kong by $40 \%$ since 2017, which shows the increasing demand for this profession. Hong Kong art therapists have been navigating different ways to apply art therapy in different settings due to a minimal understanding or acceptance of mental health support (Wong, 2014).

Insufficient understanding or acknowledgment of mental health and mental health professions in general among the Hong Kong Chinese perpetuates the lack of a local licensure system that recognizes and monitors these professions. The number of jobs available for art therapists locally is significantly fewer than that in countries with extensive professional networks, licensure boards, and postgraduate level programs. Many foreign-registered professionals who return to Hong Kong often choose to 
establish their own private practice or adapt to roles where they may concurrently practice art therapy.

Compared with home-based medical support by occupational therapists, physiotherapists, and registered nurses, home-based psychotherapeutic interventions remain minimal and understudied internationally (Sezaki \& Bloomgarden, 2000). Hong Kongers often seek home-based services due to various biopsychosocial challenges that hinder them from attending therapy in traditional office settings (Yang, Garis, Jackson \& McClure, 2009). Moreover, with a deeper psychosocial and cultural-historical understanding of Hong Kong and its people, home-based art therapy is a valid and accessible means for people in need.

\section{Psychosocial and Cultural-Historical Background}

Hong Kong has a rich colonial history, and currently, the special administrative region has been experiencing extended civil unrest since June 2019 (Cheung, Lam, \& Leung, 2019). Hong Kong and its people have been continually experiencing identity shifts over the past two centuries. Existing within every Hong Konger's psyche is the constant negotiation of Eastern and Western value systems (Lee \& Au, 2019). Confucianism family structure and capitalistic values enforce feelings of shame and hesitation that prevent people from seeking mental health support. Consequently, consideration of home-based modalities become more appealing to this population.

"Home" in Western culture often means the place where a person lives permanently, especially with family or a part of a household. In contrast, the Hong Kong Chinese definition of a home, or 家 (jia), is synonymous with the traditional Confucianism Chinese family, which includes ties with kinship groups. Kinship groups, also known as 族 $(z u)$, include the extended family, family friends, and the network of individuals who share the family name without biological ties (Wong, Yoo, \& Stewart, 2006). The structure of family is overruled by a set of moral codes to maintain peace. When a family experiences disruption in harmony, they tend to keep the issues or struggles within the family to protect its reputation (Tait, Fung, Hu, Sweller, \& Wang, 2016). Home-based therapy presents a challenge to bring changes to an exposed family system as well as an opportunity for healing for all the members involved.

Acknowledging the role of the recent political developments in Hong Kong in relation to the decline in the population's mental health status is crucial ( $\mathrm{Ng}, \mathrm{Zhang}, \mathrm{Ng}$, Wong, \& Lee, 2018). Local and social media widely circulate violent imagery without prior explicit warning to viewers, which could potentially cause viewers, who may or may not be actively participating in the protests, to experience an increase in stress level (Bodas, Siman-Tov, Peleg, \& Solomon, 2015). The daily lives of individuals are affected by road or public transit closures (Leung \& Law, 2019). Increased distrust of government entities corresponds with citizens' growing concern over retaliation or loss of future opportunities (Bramham, 2019). Personal relationships have become strained due to different stances regarding political issues. The psychological impact of the recent events in Hong Kong is evident, and difficulties associated with regular access to mental health care increased with the threat of traveling through protest-affected areas 
(Lew \& Cheung, 2019). Home-based therapeutic interventions may become a more viable and accessible option to the public as political events, which affect the public's ability to receive adequate support, go on.

Taking all the background information into consideration, the following case is presented to illustrate the possibilities and complexities of providing home-based art therapy treatment. In the following case, the therapist entered the home with sensitivity in order to witness the needs, strengths, and possible family dynamics in the client's life at home. Household members were not a part of the treatment, even though the client's parents did provide updates on the client's behavior outside of the sessions.

\section{Case Illustration: $\mathbf{Z}$}

Z, a 14-year-old who identifies as female, who was born and raised in Hong Kong, was clinically diagnosed with anxiety and depression. The client was on psychotropic medicine and was mostly house bound for a year prior to beginning art therapy. $\mathrm{Z}$ resisted all forms of conventional talk therapy. Z's parents decided to seek home-based art therapy as a last resort option, per Z's psychiatrist's suggestion. The client's parents explained the client's situation, and the therapist established some environmental requirements for sessions to be done at home.

$Z$ lives in a three-bedroom apartment building atop a busy train station and mall in Hong Kong. She lives with her parents and a domestic helper. Z's brother, who is studying in the United States, visits Hong Kong during the holidays. The family has three cats, whom $\mathrm{Z}$ adores and often holds when she is discussing topics that she feels hesitant to share. The therapy sessions happened in the living/dining area.

Digital art was a personal hobby of Z. She had been creating drawings and uploading them to social media regularly. She shared that she was not very familiar with art making with raw materials but was open to experimentation. The therapist introduced an in-home art therapy modality to $Z$, and future sessions were scheduled. The therapy goals for $\mathrm{Z}$ were the following:

- to relax and enjoy the creative process;

- to explore and understand herself better;

- to enhance her ability to communicate with others in a healthy manner.

$\mathrm{Z}$ was initially reluctant to begin but appeared optimistic in the early sessions. She started by creating art using more conventional art materials such as pencils and paper. $\mathrm{Z}$ was cautious and stated that she did not feel comfortable using colors as she "could easily mess things up." After a few sessions, $\mathrm{Z}$ eventually expanded into using colored pencils and watercolors (Figure 1).

Discussions throughout the sessions often centered on Z's interests in horseback riding and video gaming. She actively avoided discussions of school and her struggles with her family. $\mathrm{Z}$ appeared to be more relaxed and talkative as the sessions continued. She shared her active support in the protests, her relationships with family members, and the family history. $\mathrm{Z}$ also shared her social life and experiences of being bullied in school. 


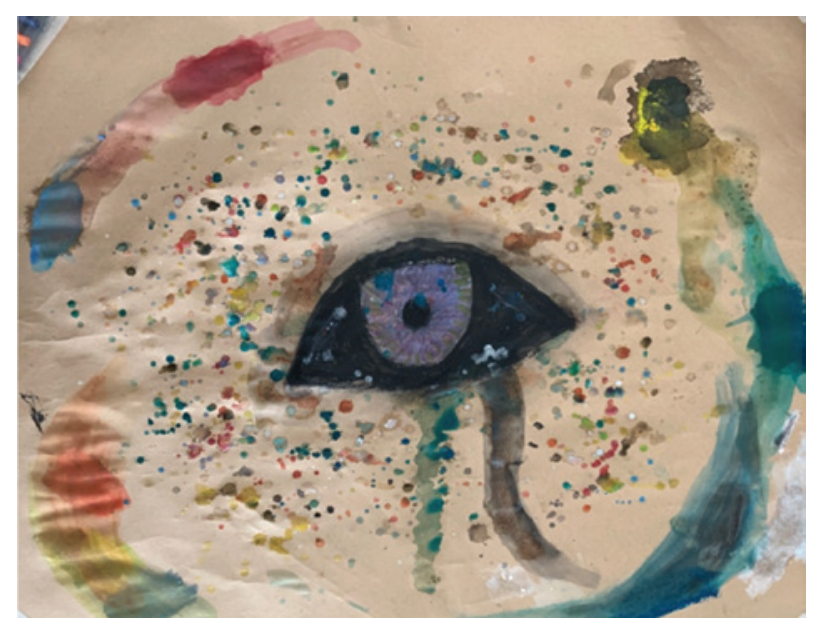

FIGURE 1 | Watercolor and pencil on brown paper.

As her therapy progressed, $\mathrm{Z}$ showed interest in using resin in her art making, as she had recently been admiring resin art on social media.

Resin as a material begins in a fluid state and turns hard when finished. The tools required to work with the material also differ depending on its changing viscosity. The selection of resin as a material reflects her emotional state, as the process involves mixing resin with inks and dyes to achieve different levels of transparency and translucency, which represent Z's ability and desire to reveal herself in therapy. The shifts in the resin in both the working and curing processes are metaphorical of her life, as they require the artist to be patient and flexible in adapting to the final outcome. $Z$ was motived to research the process with the therapist by creating a shopping list of materials needed to create the art she envisioned, which included selecting the type of resin, rubber gloves, mixing tools, ink colors, glitter, and sand. Additionally, Z prepared the home environment by creating a space with suitable ventilation and reviewed online tutorials. $\mathrm{Z}$ was highly engaged in creating resin art. A few months into creating resin pieces, $\mathrm{Z}$ shared her plans to open an online store with her parent to sell her art (Figure 2). With encouragement from her family and the therapist, $\mathrm{Z}$ showed dramatic development as an artist and was able to attend school a few days a week on a regular basis.

\section{Discussion}

Rather than dwelling on her perceived deficit, $\mathrm{Z}$ utilized the art process to embody her artistic strength and identity. Her interest in engaging with the new media empowered her to consider starting a business, showing an increased sense of self-accomplishment. She was able to apply creativity within her life beyond the art process. $Z$ was able to engage more positively with her parents, which in turn improved her family dynamics.

The parallel development of the client learning to use a new material (resin) as the therapeutic alliance increased was crucial in the process. The media of choice were 


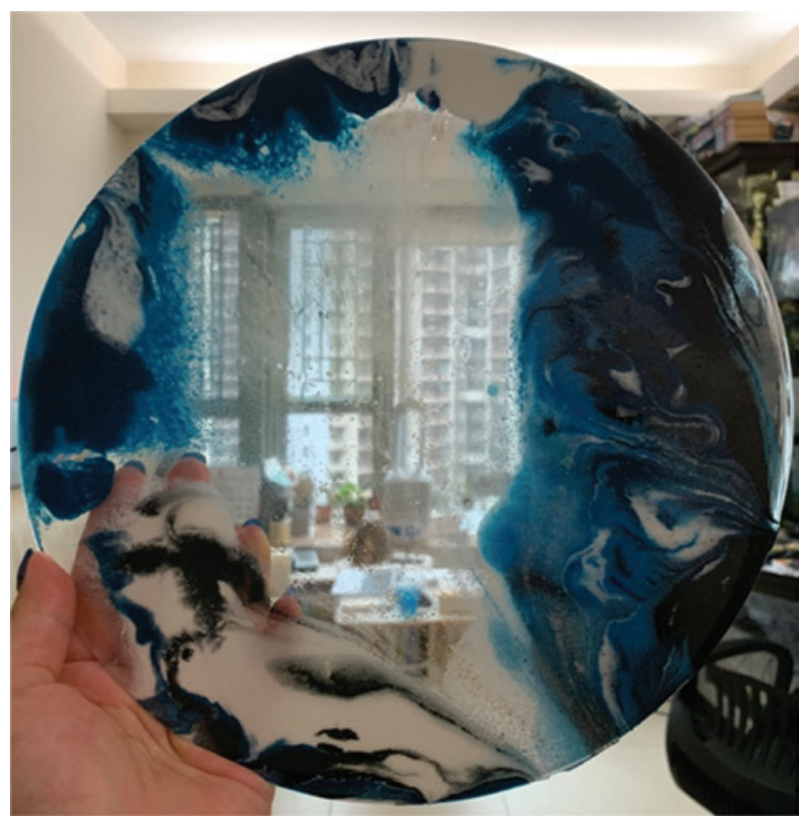

FIGURE 2 | Resin art created on an acrylic panel, documented against the background of the client's home.

reflective of the therapeutic process, as they reveal the client's functional level and progress toward the therapeutic goals (Moon, 2002). Z was able to learn and build resilience from the process of each piece and modified her methods accordingly. Her choice of resin reflected her willingness to work with difficult materials, which implies her readiness to apply the skills she learned in the creative process into to her own life. $\mathrm{Z}$ connected the similarities between the process of life and the creative process. She was able to creatively solve issues that came up in art and in her interpersonal issues. The home-based art therapy process is focused on the clients' strengths while supporting them to explore possible solutions to challenges, and the home provided a sense of security while the client made challenging psychological shifts.

The home-based art therapy model presents a set of advantages and disadvantages in this particular case. Z was able to establish rapport with the therapist quickly, as she was in her familiar environment. $\mathrm{Z}$ also displayed the ability to stretch her resilience by working with struggles and with her willingness to explore unfamiliar aspects of herself. The home-based art therapy modality became the stepping-stone to providing additional support for her increased engagement with the community outside of her home. Within the privacy of the Z's home, she was able to freely discuss her opinions related to the current sociopolitical events in Hong Kong. Conversely, this modality may have delayed Z's ability or willingness to expand beyond her home due to the accessibility of in-home support. The flexibility of the home setting presented a set of challenges to ensure psychological, emotional, and relational safety. 
Due to the limited space at Z's home, in-home art therapy happened in the living room. Her family members at times passed through the living room depending on the time of day or stayed in different rooms of the home. The unexpected aspect of the home-based therapeutic environment prompted her to struggle with staying engaged in sensitive topics or difficult emotions. To counteract instances of compromised emotional safety, the therapist established a firm routine regarding the flow of every session and consistently drew boundaries with family members by stressing the importance of confidentiality. However, the limited sense of safety felt by $\mathrm{Z}$ is evident in the layers of communication involved in relating to her plan of care.

The layers of communication established by $Z$, the caregiver, and the treatment team members increased the complexity of the therapeutic process. Z's caregiver played the role of a case manager who coordinates Z's mental health-care team of psychiatrist, psychologist, school, tutors, and therapists. Without adequate communication or transparency among these different supports, the care provided for $Z$ was disjointed and compartmentalized. Z's caregiver provided reasons for revealing only certain aspects of Z's treatment to her school, which was fear of judgment from the academe, which may affect Z's likelihood to get into her desired universities in the future. Concerns relating to shame and fear of affecting one or the family's reputation for seeking mental health support present a disadvantage for families to fully utilize an underdisciplined support network.

\section{Boundaries in Home-based Art Therapy}

Similar to the unique difference between providing services in an institutional setting and the environmental settings that are far more researched in the art therapy field (Whitaker, 2017), working in a home-based setting can be regarded as another adaptation of any physical and therapeutic space. This unique setting comes with its own set of challenges, expectations, ethical dilemmas, and role adaptation for the therapist (Sezaki \& Bloomgarden, 2000; Yang, Garis, Jackson, \& McClure, 2009; Zur, 2015). Not only does the therapist have to prepare to establish appropriate physical boundaries, one must also consider the psychological boundaries to ensure safety when working with individuals and their families in this specialized setting.

Boundary establishment is the key to providing safety in order to begin and sustain any therapeutic relationship. Communication with the family prior to the beginning of sessions regarding therapeutic space requirements is crucial. Understanding the small living spaces available in Hong Kong, minimizing distraction and interruption is advised. Suggestions include turning off the television and telephones and notifying people who may pass through the therapy space ahead of time. As interruptions may still occur, these incidents may provide insights into the social dynamic among family members or caregivers. Additionally, the therapist can also assess the client's needs and make constructive adjustments in therapy (Yang et al., 2009).

Home-based art therapy presents certain benefits and challenges to a therapeutic relationship. Although some clients may consider this modality as more suitable for them to open up, others might find the home-based method intrusive and overwhelming. The 
home can provide a safe and comfortable environment for exploration and expression (Sezaki \& Bloomgarden, 2000). Clients being in a familiar environment or with pets around can allow easier establishment of rapport. This sense of comfort may also present certain relational challenges in client compliance or ethical issues. Additionally, the concept of confidentiality comes to the forefront in the context of shifting boundaries due to cultural differences.

The concept of confidentiality in the East differs with that of the West. Due to the collectivist culture, individual health and mental health are often closely linked to the larger context of one's family. Family expectations, values, and structure play a major role in the shaping of mental- or physical health-related decisions (Rodriguez, Fang, Gao, Robins, \& Rosenthal, 2016). For instance, doctors may communicate a diagnosis to family members, who may or may not reveal the diagnosis or prognosis to the patient. Therefore, in the context of mental health care, the sense of responsibility of caregivers at times drives them to disregard emotionally sensitive topics and interject their own projections to mental or physical health care. The blurred boundaries between public and private can challenge the Western concepts of ethical boundaries.

Ethical and boundary crossing issues such as personal or family invitations, inappropriate gifts, and advances may arise due to increased intimacy (Camper \& Taitt, 2011, as cited in Camper, 2016). Therapeutic implications of simple gestures become highlighted in a home-based therapeutic environment. For instance, accepting a glass of water or a piece of candy, which is a custom when visiting someone's home during certain holidays like Chinese New Year, is a realistic example of what would be considered ethically challenging in the traditional Western mindset (Schultz, Baraka, Watson, \& Yoo, 2020), and a therapist may seem stiff and unapproachable in the therapeutic relationship when Western ethical guidelines are followed without a critical understanding or application to the Hong Kong Chinese culture (Deng, Qian, Gan, Hu, Gao, Huang, \& Zhang, 2016).

Situations that may challenge the traditional ethical boundaries can still happen despite the extensive preparation one might do. Therefore, the therapist must prioritize his/her own safety and regular supervision or clinical consultation to maintain quality of services provided and to protect one from emotional burnout (Zur, 2015). As sensitive topics relating to current political events may come up during sessions, the therapist must prioritize their own mental health by attending personal therapy to maintain awareness of possible transference or countertransference. A home-based therapist is also advised to screen and brief individuals or families regarding this modality to determine the suitability to this type of treatment.

\section{The Home-based Art Therapist}

To manage the ever-changing nature of a home setting, a home-based art therapist should be flexible, organized, and assertive (McElroy, Warren, \& Jones, 2006). With increased disruption to transportation options due to recent political events, therapists must be mindful of the preparation and transportation of materials and be aware of their own safety when traveling to and from clients' homes. Additionally, openness and curiosity 
are both essential to be culturally competent and sensitive to one's strengths, needs, abilities, and preferences for optimal treatment outcome. The home-based therapist must respond to unexpected events or family dynamics in a positive therapeutic manner to readily model for the client or the family healthy ways to relate with one another.

The home can nurture the creativity and imagination in the collaborative relationship shared by a therapist and his/her client(s). Utilizing the available materials and rearranging furniture can allow people to experience a space differently, seeing the home in a new perspective. The creative process becomes empowering and transformative to the home and the people who live in it.

\section{Conclusion}

The development of home-based art therapy is based on the strengths of the home environment combined with the clinical and artistic expertise of home-based art therapists. Home-based art therapy exists in Hong Kong with its own unique set of benefits and challenges compared to traditional settings. This modality presents new areas for research to deepen the understanding of how home-based art therapy is a valid and valuable part of the larger art therapy landscape, especially in a culturally unique place like Hong Kong.

\section{About the Author}

Ling Cheun Bianca Lee is an artist, advocate, board-certified registered art therapist (USA), licensed professional clinical counselor (USA), and licensed professional counselor (USA). She lived and worked in the United States for years before returning to Hong Kong to collaborate with people from all walks of life. Bianca currently runs a private practice. She is the current president of the Hong Kong Association of Art Therapists and an honorary lecturer at the University of Hong Kong.

\section{References}

Bodas, M., Siman-Tov, M., Peleg, K., \& Solomon, Z. (2015). Anxiety-inducing media: The effect of constant news broadcasting on the well-being of Israeli television viewers. Psychiatry-Interpersonal and Biological Processes, 78(3), 265-276.

Bramham, D. (2019). Daphne Bramham: Even in Canada, Hong Kong supporters fear retaliation. Vancouver Sun. Retrieved [January 16 ${ }^{\text {th }}, 2020$ ], from https://vancouversun.com/opinion/columnists/ daphne-bramham-even-in-canada-hong-kong-supporters-fear-retaliation.

Camper, C. (2016). An exploration of home-based therapists' supervisory experiences: A phenomenological inquiry (Doctoral dissertation). Retrieved [January $\left.16^{\text {th }}, 2020\right]$, from http://nsuworks.nova.edu/shss_dft etd/16.

Cheung, G., Lam, J., \& Leung, C. (2019). Four months of Hong Kong protests: How peaceful mass marches escalated to intense violence, a bitterly divided society and a loss of innocence. South China Morning Post. Retrieved [January 16 ${ }^{\text {th }}, 2020$ ], from https:/www.scmp.com/news/hong-kong/politics/ article/3032073/innocence-lost-how-hong-kong-fell-peaceful-mass-marches.

Deng, J., Qian, M., Gan, Y., Hu, S., Gao, J., Huang, Z., \& Zhang, L. (2016). Emerging practices of counseling and psychotherapy in China: Ethical dilemmas in dual relationships. Ethics \& Behavior, 26(1), 63-86.

Hong Kong Association of Art Therapists (HKAAT). (2019). About HKAAT. Retrieved [January 16 ${ }^{\text {th }}$, 2020], from http://www.hkaat.org/index.php/art-therapy/about. 
Lee, B. L. C., \& Au, R. W. Y. (2019). Mediating the cultural boundaries: Rise of the lion rock spirit in Hong Kong women. In S. Hogan (Ed.), Gender difference in arts therapies (pp. 84-98). London: Routledge.

Leung, K., \& Law, L. (2019). Angry residents confront Hong Kong's MTR staff over closure of train services and stations on Kwun Tong line before protest march. South China Morning Post. Retrieved [January $\left.16^{\text {th }}, 2020\right]$, from https://www.scmp.com/news/hong-kong/transport/article/3024198/hongkongs-mtr-corp-announces-suspension-train-services.

Lew, L. \& Cheung, E. (2019). Mental health in Hong Kong at its worst level in eight years, affected by ongoing social unrest: Survey. South China Morning Post. Retrieved [January 16 ${ }^{\text {th }}, 2020$ ], from https://www.scmp.com/news/hong-kong/health-environment/article/3032234/mental-health-hongkong-its-worst-level-eight.

McElroy, S., Warren, A., \& Jones, F. (2006). Home-based art therapy for older adults with mental health needs: Views of clients and caregivers. Art Therapy, 23(2), 52-58.

Moon, C. (2002). Studio art therapy: Cultivating the artist identity in the art therapist. London and Philadelphia, PA: Jessica Kingsley Publishers.

Ng, S. L., Zhang, Y., Ng, K. H., Wong, H., \& Lee, J. W. Y. (2018). Living environment and quality of life in Hong Kong. Asian Geographer, 35(1), 35-51.

Rodriguez, M., Fang, C., Gao, J., Robins, C., \& Rosenthal, M. (2016). Perceptions of the limitations of confidentiality among Chinese mental health practitioners, adolescents and their parents. Ethics \& Behavior, 26(4), 344-356.

Schultz, T., Baraka, M., Watson, T., \& Yoo, H. (2020). How do ethics translate? Identifying ethical challenges in transnational supervision settings. International Journal for the Advancement of Counselling, 42(3), 234-248.

Sezaki, S., \& Bloomgarden, J. (2000). Home-based art therapy for older adults. Art Therapy: Journal of the American Art Therapy Association, 17(4), 283-290.

Tait, K., Fung, F., Hu, A., Sweller, N., \& Wang, W. (2016). Understanding Hong Kong Chinese families' experiences of an autism/ASD diagnosis. Journal of Autism and Developmental Disorders, 46(4), 1164-1183.

Whitaker, P. (2017). Art therapy and environment (Art-thérapie et environnement). Canadian Art Therapy Association Journal, 30(1), 1-3.

Wong, O. (2014). Contextual barriers to the successful implementation of family-centered practice in mental health care: A Hong Kong study. Archives of Psychiatric Nursing, 28(3), 212-219.

Wong, S. T., Yoo, G. J., \& Stewart, A. L. (2006). The changing meaning of family support among older Chinese and Korean immigrants. Journal of Gerontology Series B: Psychological Sciences and Social Sciences, 61(1): 4-9.

Yang, J. A., Garis, J., Jackson, C., \& McClure, R. (2009). Providing psychotherapy to older adults in home: Benefits, challenges, and decision-making guidelines. Clinical Gerontologist, 32(4), 333-346.

Zur, O. (2015). In-home therapy and home visits. Retrieved [January 16 ${ }^{\text {th }}, 2020$ ], from https://www. zurinstitute.com/home_based_mental_health.html. 